\section{Commentary: Aortic valve repair-from art to science}

\author{
Munir Boodhwani, MD, MMSc
}

The term "art" has been applied to much of what cardiac surgeons do. Indeed, the concept of art as it applies to surgery may be defined as an ability or skill that one develops with training and practice. It is a task involving creativity and imagination. It also implies that each product is its own unique creation, not easily reproducible, and thus difficult, if not impossible, to teach. Much of what may be mundane to an experienced surgeon may seem like art to the uninitiated observer, but yet when one distills the foundational principles that drive decision making, some unifying concepts emerge.

The discipline of aortic valve (AV) repair emerged in the late 1980s and 1990s with the advent of two different approaches to valve-sparing root replacement, the reimplantation and remodeling approaches. These operations forced surgeons to develop a thorough understanding of the relationships between annular geometry and cusp function. These concepts were first used to enable the preservation of morphologically normal aortic valves but were soon extended to treat cusp pathology, which was either a primary or an associated cause of aortic insufficiency (AI). In those early days, valve-sparing root replacement and $\mathrm{AV}$ repair were seen as artistic operations, elusive and difficult to master even in the hands of active aortic surgeons; however, the past 15 years have brought tremendous gains in the understanding of $\mathrm{AV}$ and root geometry and their interactions, the classification of mechanisms of AI that enables understanding and communication, ${ }^{1}$ and

From the Division of Cardiac Surgery, University of Ottawa Heart Institute, Ottawa, Ontario, Canada.

Disclosures: The author reported no conflicts of interest.

The Journal policy requires editors and reviewers to disclose conflicts of interest and to decline handling or reviewing manuscripts for which they may have a conflict of interest. The editors and reviewers of this article have no conflicts of interest.

Received for publication April 6, 2021; revisions received April 6, 2021; accepted for publication April 6, 2021; available ahead of print April 10, 2021.

Address for reprints: Munir Boodhwani, MD, MMSc, Division of Cardiac Surgery, University of Ottawa Heart Institute, H3405, 40 Ruskin St, Ottawa, Ontario, Canada K1Y 4W7 (E-mail: mboodhwani@ottawaheart.ca).

JTCVS Techniques 2021;7:128-9

2666-2507

Copyright (C) 2021 Published by Elsevier Inc. on behalf of The American Association for Thoracic Surgery. This is an open access article under the CC BY-NC-ND license (http://creativecommons.org/licenses/by-nc-nd/4.0/).

https://doi.org/10.1016/j.xjtc.2021.04.002

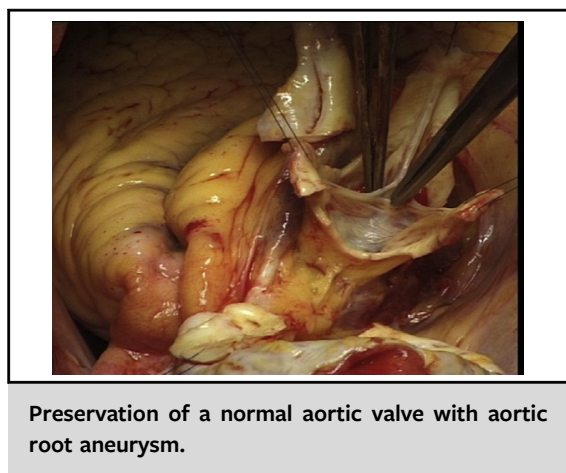

CENTRAL MESSAGE

Aortic valve repair has evolved to

a discipline with core guiding

principles developed through

careful scientific analysis of aortic

valve anatomy and function and

valve repair outcome data.

the development and scientific evaluation of a repertoire of techniques and materials to assess and address annular and leaflet pathology, along with a critical analysis of outcomes that has identified key determinants of long-term repair durability. These developments have transformed the field of AV repair from one that was accessible to only a few to one that can be performed safely by those with sufficient expertise and case volume.

When we now evaluate a patient with AI for consideration of repair, we should be able to identify and classify the mechanism based on leaflet morphology, jet characteristics, and annular dimensions. We should be able to predict the repair techniques that will likely be required. We should have clear targets for annular diameter and leaflet coaptation (coaptation length, $\geq 5 \mathrm{~mm}$; effective height, $\geq 9 \mathrm{~mm})^{2}$ that we want to leave behind. Although there is a learning curve to understanding and applying these concepts (estimated at $\sim 40-50$ cases), ${ }^{3}$ a number of validated scientific principles guide AV repair surgery.

In this issue of JTCVS Techniques, Dr Svensson ${ }^{4}$ highlights some of these core principles developed from his own significant experience and techniques used at the Cleveland Clinic. This article adds to the work by pioneers in this field that have enabled a systematic study of AV repair through observation and experimentation, the very definition of science. It is only through the scientific 
application of these core principles that we will achieve sustained improvements in and reproducible, widespread application of $\mathrm{AV}$ repair.

\section{References}

1. Boodhwani M, de Kerchove L, Glineur D, Poncelet A, Rubay J, Astarci B, et al. Repair-oriented classification of aortic insufficiency: impact on surgical techniques and clinical outcomes. J Thorac Cardiovasc Surg. 2009;137:286-94.
2. le Polain de Waroux JB, Pouleur AC, Robert A, Pasquet A, Gerber BL, Noirhomme P, et al. Mechanisms of recurrent aortic regurgitation after aortic valve repair: predictive value of intraoperative transesophageal echocardiography. JACC Cardiovasc Imaging. 2009;2:931-9.

3. Malas T, Saczkowski R, Sohmer B, Ruel M, Mesana T, de Kerchove L, et al. Is aortic valve repair reproducible? Analysis of the learning curve for aortic valve repair. Can J Cardiol. 2015;31:1497.e15-22.

4. Svensson LG. The art of aortic valve repair. J Thorac Cardiovasc Surg Tech. 2021; 7:121-5. 